\title{
Global climatology and trends in convective environments from ERA5 and rawinsonde data
}

\author{
Mateusz Taszarek (iD ${ }^{1,2,3 凶}$, John T. Allen ${ }^{4}$, Mattia Marchio ${ }^{5,6}$ and Harold E. Brooks ${ }^{2,7}$
}

Globally, thunderstorms are responsible for a significant fraction of rainfall, and in the mid-latitudes often produce extreme weather, including large hail, tornadoes and damaging winds. Despite this importance, how the global frequency of thunderstorms and their accompanying hazards has changed over the past 4 decades remains unclear. Large-scale diagnostics applied to global climate models have suggested that the frequency of thunderstorms and their intensity is likely to increase in the future. Here, we show that according to ERA5 convective available potential energy (CAPE) and convective precipitation (CP) have decreased over the tropics and subtropics with simultaneous increases in 0-6 km wind shear (BS06). Conversely, rawinsonde observations paint a different picture across the mid-latitudes with increasing CAPE and significant decreases to BS06. Differing trends and disagreement between ERA5 and rawinsondes observed over some regions suggest that results should be interpreted with caution, especially for CAPE and CP across tropics where uncertainty is the highest and reliable long-term rawinsonde observations are missing.

npj Climate and Atmospheric Science (2021)4:35; https://doi.org/10.1038/s41612-021-00190-x

\section{INTRODUCTION}

Globally, thunderstorms present a significant hazard to communities, agriculture, and infrastructure. Recent analysis of the direct economic losses as a result of convective events suggests that over Europe and North America altogether, around 300 billion USD in damage has been reported over the last decade ${ }^{1}$. Thunderstorms produce a variety of hazards that lead to fatalities, including heavy precipitation with flash flooding ${ }^{2}$, lightning ${ }^{3}$, large hail $^{4}$, damaging winds ${ }^{5}$ and tornadoes ${ }^{6}$. As direct observations of many of these phenomena are sparse, a typical approach has been to identify key ingredients necessary to their formation ${ }^{7}$, and use them as a proxy for assessing climatological frequency and intensity of severe convective storms, a technique well validated by observations ${ }^{8-10}$. A proxy of convective available potential energy (CAPE) is often considered, as it provides an approximation to the theoretical maximum updraft speed $(w=\sqrt{2 \times C A P E})$ in convective clouds ${ }^{11,12}$. The severity and longevity of thunderstorms can be then characterized by the environmental wind shear that governs storm organization ${ }^{13-15}$. Finally, to better anticipate the likelihood of storms initiating in a favorable environment, proxies such as modeled convective precipitation are also considered ${ }^{10,16,17}$.

Thunderstorm frequency and intensity has been shown to be changing regionally over recent decades ${ }^{18-22}$. However, how this translates globally is unclear as many of these changes are linked to complex regional circulation features. Our current understanding of future changes in convective environments induced by a globally warming climate is that large increases to low-level moisture (and thus CAPE) will result in the atmosphere being more conducive for severe thunderstorms $s^{23-27}$ and heavy precipitation ${ }^{28-31}$. However, these projections have large uncertainty with more recent studies indicating significant decreases $(\sim 15 \%)$ to lightning flash rate under global warming or mixed trends $^{32,33}$, particularly in the tropics ${ }^{29,34}$.

This uncertainty raises the question of what changes have occurred historically for favorable convective environments globally, and how do these compare to future expectations. The availability of recently released global ERA5 reanalysis with hourly resolution and horizontal spacing sufficient to sample local scale convective environments, allows construction of a global climatology and analysis of corresponding trends in the way that was not possible with prior reanalyses ${ }^{35,36}$. However, as each reanalysis features certain limitations related to model formulation, applied parameterizations and assimilation techniques, a validation using observed sounding profiles is necessary ${ }^{37-39}$. Thus, results based on reanalyses should be always interpreted with caution, especially concerning thermodynamic instability and modeled precipitation where systematic errors are present ${ }^{39,40}$.

\section{RESULTS}

\section{Convective available potential energy}

The climatological distribution of CAPE strongly reflects the availability of low-level moisture. Enhanced CAPE is observed over tropical and subtropical zones, excluding the high-pressure areas over the oceans and subtropical deserts (Fig. 1a). The $95^{\text {th }}$ percentile (P95) of the CAPE distribution exceeds $5000 \mathrm{~J} \mathrm{~kg}^{-1}$ over the warm waters surrounding the Arabian Peninsula (Red Sea, Persian Gulf) and eastern coast of India. Over land, the highest CAPE is typically observed over Congo Basin (P95 of around $3000 \mathrm{~J} \mathrm{~kg}^{-1}$ ).

Trend analysis of P95 CAPE over the last 4 decades indicates significant decreases across tropical and subtropical zones, with changes of as much as $-200 \mathrm{~J} \mathrm{~kg}^{-1}(\sim 5-10 \%)$ per decade (Fig. 1a), that also contribute to significant reductions in the frequency of

\footnotetext{
${ }^{1}$ Cooperative Institute for Mesoscale Meteorological Studies, University of Oklahoma, Norman, OK, USA. ${ }^{2}$ National Severe Storms Laboratory, Norman, OK, USA. ${ }^{3}$ Department of Meteorology and Climatology, Adam Mickiewicz University, Poznań, Poland. ${ }^{4}$ Department of Earth and Atmospheric Sciences, Central Michigan University, Mount Pleasant, MI, USA. ${ }^{5}$ Atmospheric Physics Group, Department of Civil, Environmental and Mechanical Engineering - DICAM, University of Trento, Trento, Italy. ${ }^{6}$ C3A - Center Agriculture Food

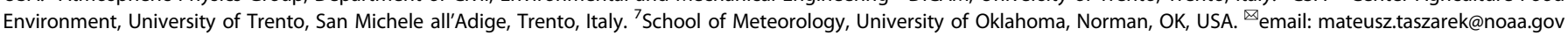


a)
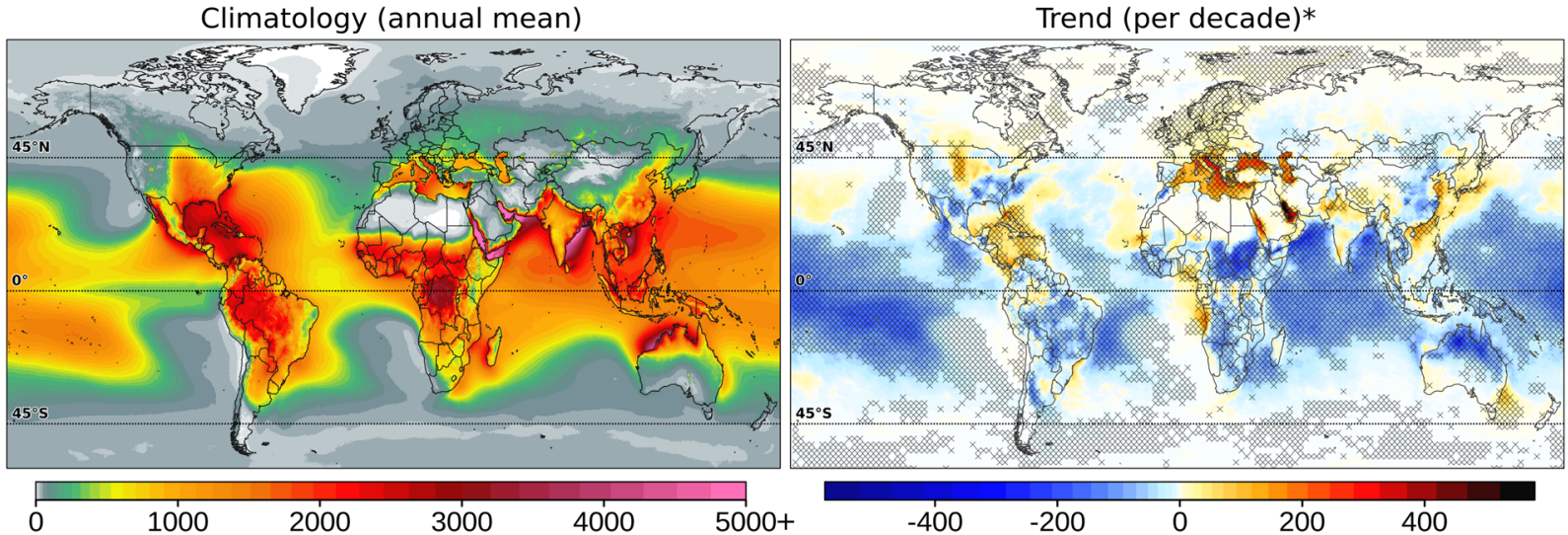

b)

Accumulated convective precipitation [mm]
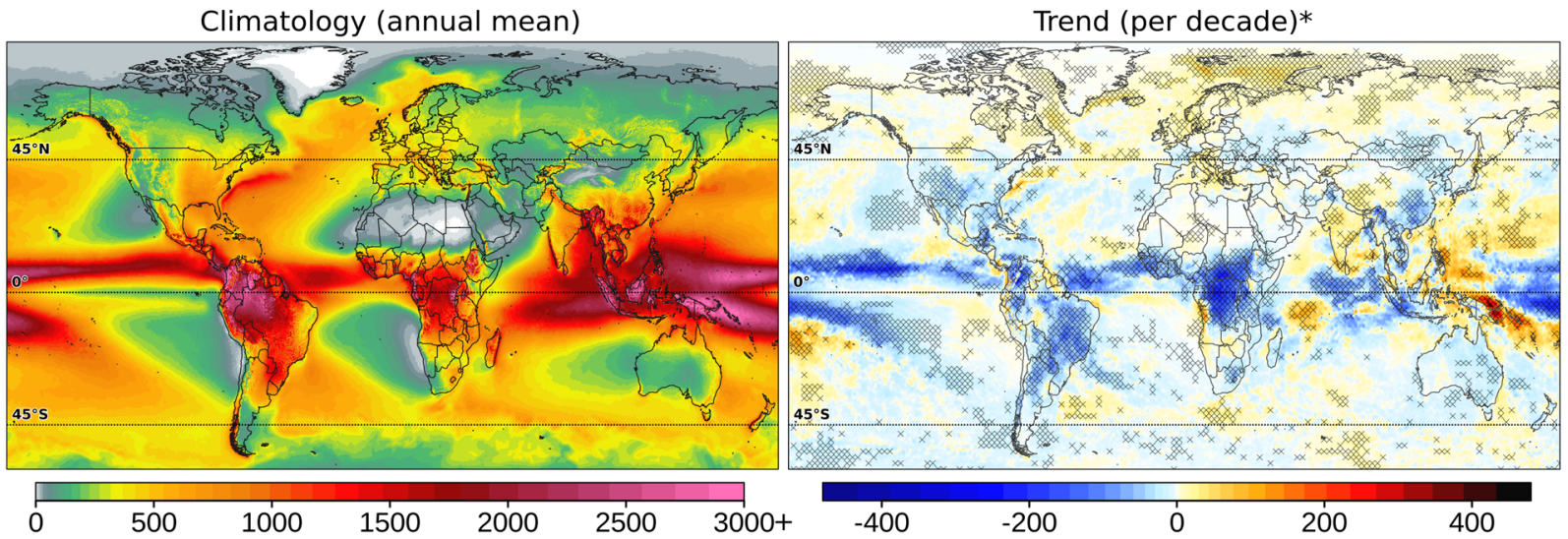

C)

$50^{\text {th }}$ percentile of $0-6 \mathrm{~km}$ shear $\left[\mathrm{m} \mathrm{s}^{-1}\right]$
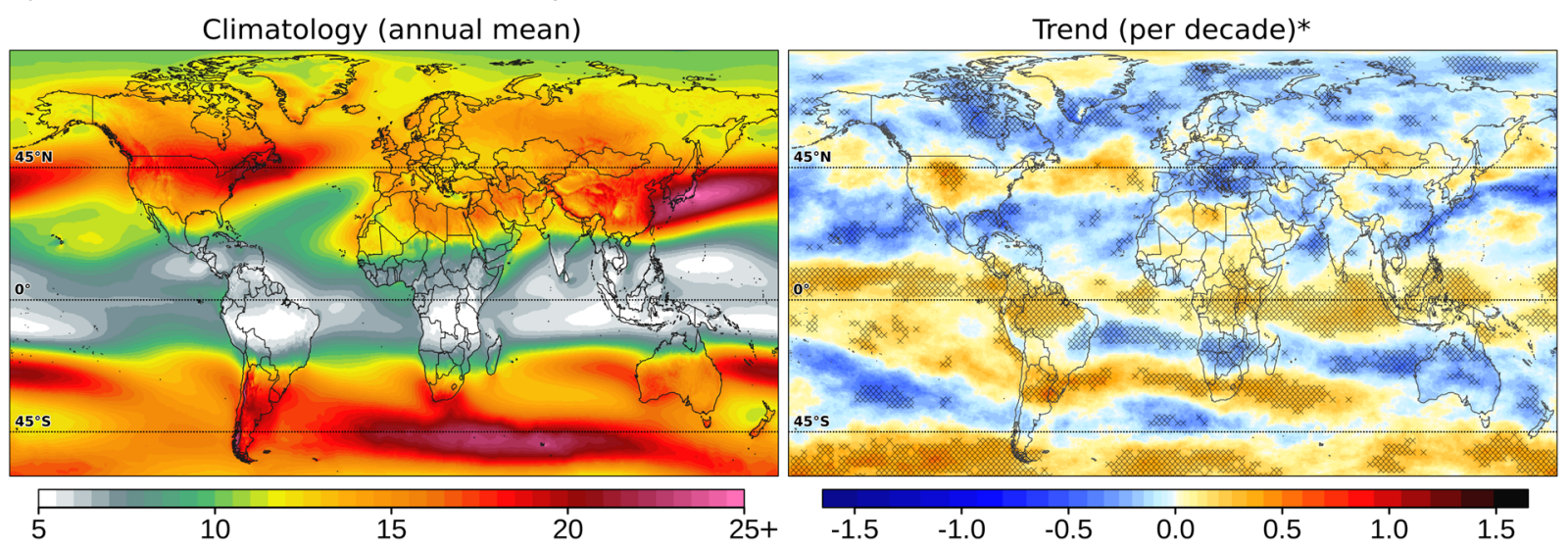

* - 'x' marks denote statistically significant trend ( $p$-value $<0.05$ )

Fig. 1 ERA5 climatology and trends for CAPE, convective precipitation and vertical wind shear. A 41-year (1979-2019) climatology and trends for the (a) $95^{\text {th }}$ percentile of convective available potential energy (CAPE), (b) accumulated convective precipitation, and (c) $50^{\text {th }}$ percentile of 0-6 km vertical wind shear. Climatology is constructed by taking a mean from annual values, and trends are computed using Sen's slope (values denote change per decade). Statistically significant trends $(p$-value $<0.05)$ are marked with ' $x$ ' symbols.

favorable thunderstorm environments (Fig. 2a). In contrast, robust increases of up to $+400 \mathrm{~J} \mathrm{~kg}^{-1}(\sim 5-15 \%)$ per decade are seen over temperate zones near inland seas and warm ocean surfaces, including the Mediterranean, Black Sea, Caspian Sea, Red Sea, in addition to the South China Sea, Persian Gulf and Gulf of Mexico. However, despite these increases over water, land-based changes are more modest and observed only over northwestern India, the northern Great Plains of the United States, and the majority of Europe.

Seasonally (Supplementary Fig. 1), negative trends in P95 CAPE follow the axis of Intertropical Convergence Zone (ITCZ), corresponding to decreases during peak heating in the respective 
a)

Thunderstorm environments [hours]**

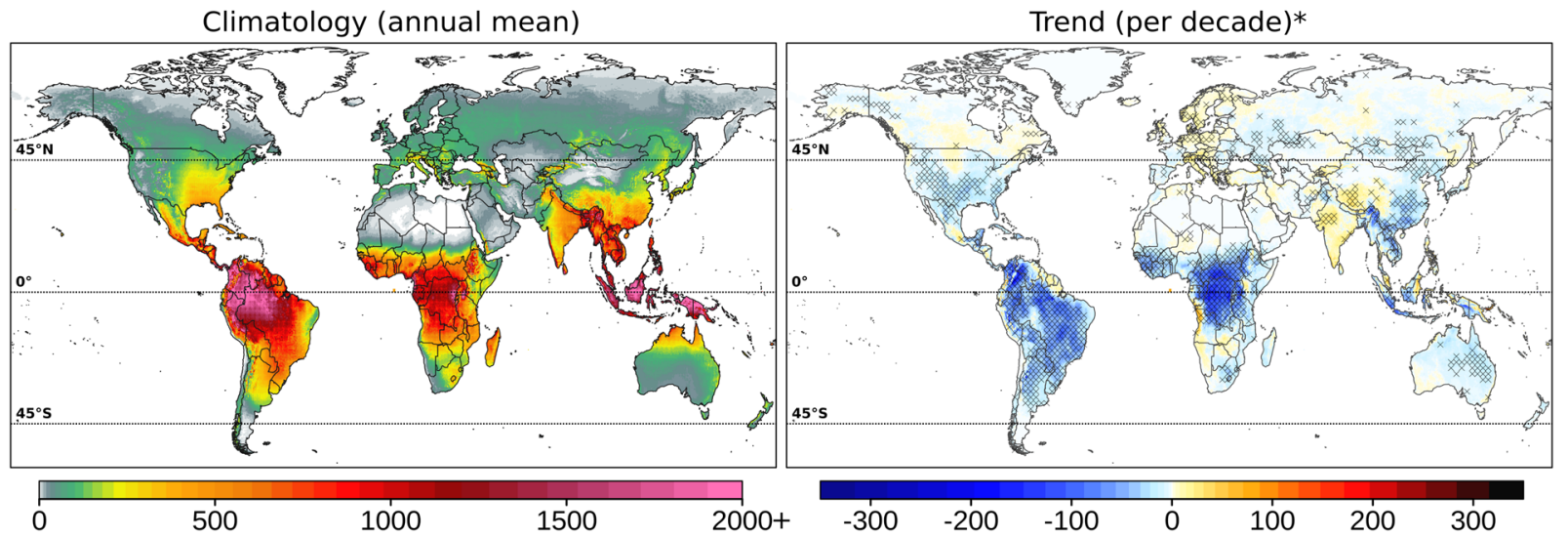

b)

\section{Severe thunderstorm environments [hours] ${ }^{* * *}$}

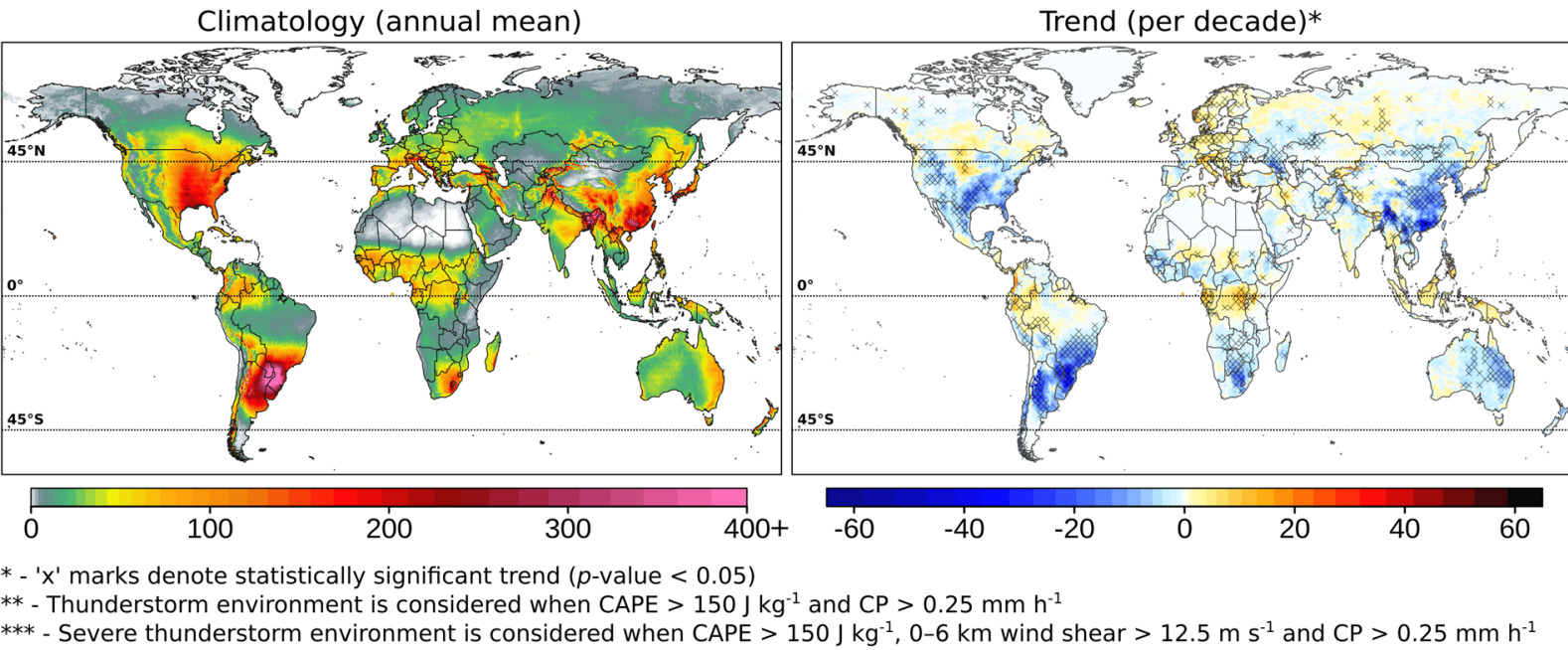

Fig. 2 ERA5 climatology and trends for thunderstorm and severe thunderstorm environments. As in Fig. 1 but with the application of a land-surface mask and showing the combined frequency proxy of (a) thunderstorm environments, and (b) severe thunderstorm environments.

hemispheric summers: JJA (June, July, August) over the north, and DJF (December, January, February) over the south. The largest decreases in P95 CAPE of $-200 \mathrm{~J} \mathrm{~kg}^{-1}(\sim 10 \%)$ per decade are observed over the eastern Sahel region during MAM (March, April, May), and northern Australia during DJF (Supplementary Fig. 1). These trends may represent the ongoing desertification in the former, and the weakness of the monsoon circulation in the latter ${ }^{41}$. Drying in the Northern Hemisphere subtropics and tropics have been also observed with decreasing trends in precipitation in 20th century by Zhang et al. ${ }^{42}$. Increases in P95 CAPE over the inland seas, Gulf of Mexico, the northern Great Plains of the United States, Europe, Persian Gulf, and eastern Asian coast are the highest during JJA and over oceans persist into SON (September, October, November).

\section{Convective precipitation}

Although CAPE provides insight into whether the atmosphere has the potential to produce deep moist convection, convective initiation is necessary for the thunderstorm to occur. This problem is highlighted over locations such as southern Texas or the western Mediterranean Sea where high CAPE rarely results in convective development due to considerable inhibition ${ }^{35,43}$. Increases in CAPE, therefore, mean little for thunderstorms if the frequency of initiation does not increase as well ${ }^{44,45}$. For this reason, we also consider changes in ERA5 modeled convective precipitation $(\mathrm{CP})$ that serve as a proxy for convective initiation.

The climatological distribution of CP (Fig. 1b) is generally similar to CAPE (Fig. 1a), with the highest CP accumulations (> $1500 \mathrm{~mm}$ per year) observed along the ITCZ and following its seasonal meridional shifts during JJA and DJF (Supplementary Fig. 2). Despite low CAPE, CP accumulations exceeding $400 \mathrm{~mm}$ per year occur over the far northern Atlantic and Europe, driven primarily by the warm waters of the Gulf Stream. Similar enhancement in CP is also observed within Kuroshiro, Agulhas, Brazilian and eastern Australian warm currents, and all cyclonically active regions in the mid-latitudes. Lower CP accumulations are observed within cold currents and regions of subtropical subsidence that inhibit convective development (e.g. South Atlantic High).

Analysis of trends in CP suggest consistent weakening of convective activity within the ITCZ, with decreases in CP accumulations on the order of $-150 \mathrm{~mm}(\sim 5-10 \%)$ per decade (Fig. 1b). An exception is the western Pacific Ocean, where local increases are observed, contrasting consistent decreases in CAPE (Fig. 1a), which may be linked to strong inter-annual climate variability in response to trans-Pacific El Niño and La Niña circulation effects ${ }^{46}$. Robust decreases are also observed over the majority of Amazonian South America, the southwestern United States, Congo Basin, southeastern 

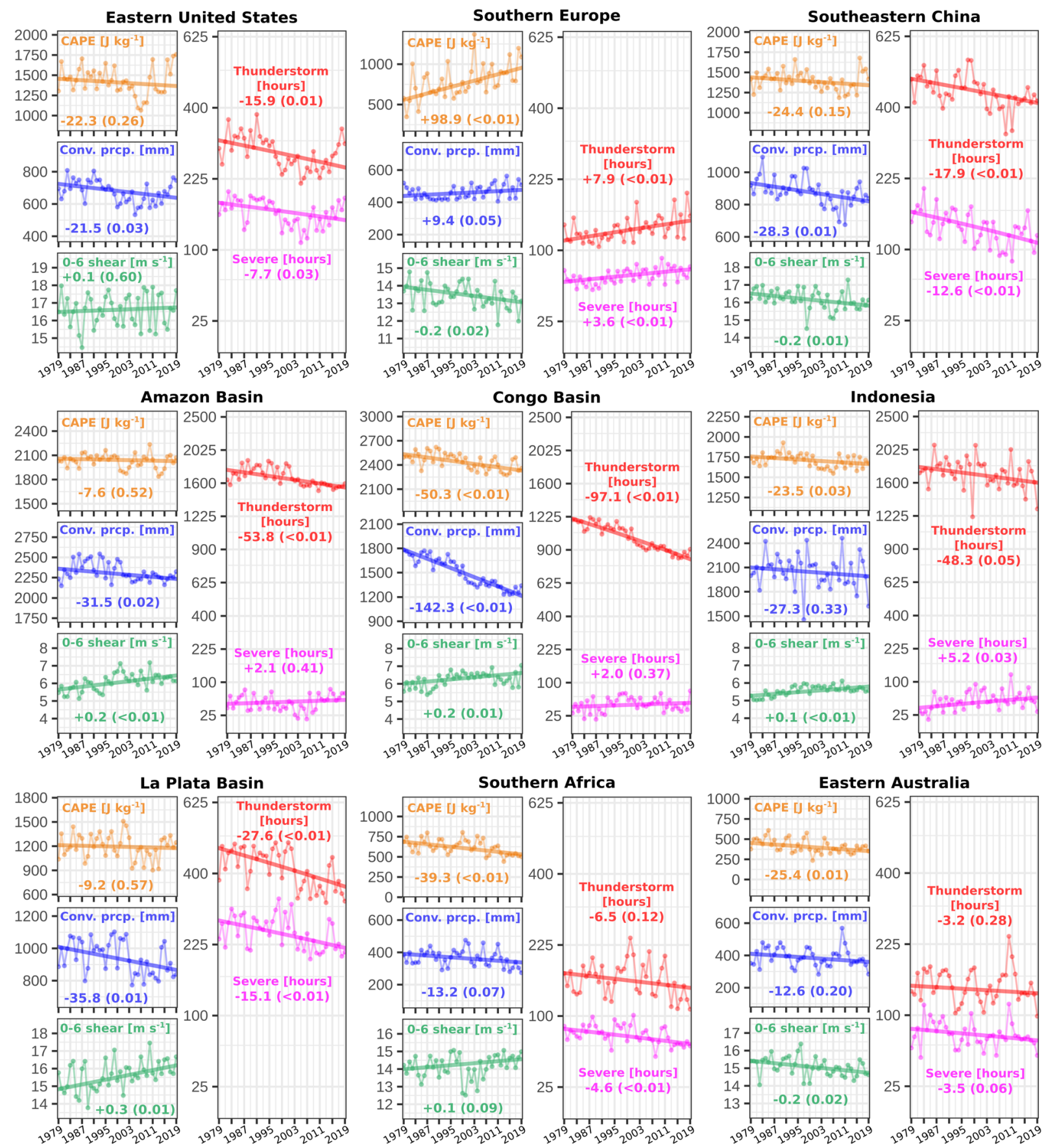

Fig. 3 ERA5 regional trends for CAPE, convective precipitation, vertical wind shear, thunderstorm, and severe thunderstorm environments. A 41-year (1979-2019) annual distribution of the (orange) $95^{\text {th }}$ percentile of convective available potential energy (CAPE), (blue) accumulated convective precipitation, (green) $50^{\text {th }}$ percentile of $0-6 \mathrm{~km}$ vertical wind shear, (red) frequency of thunderstorm environments, and (magenta) frequency of severe thunderstorm environments for specific regions (areal mean) as indicated on Supplementary Fig. 6. Trends are computed using Sen's slope and indicated as a solid line. Numbers within linear plots indicate trend per decade and $p$-value.

Asia, and eastern Australia (Figs. 1b and 3). Few areas exhibit significant increases and these are mostly modest, predominantly over the Indian subcontinent, western China, parts of southern and northern Europe, Siberia and Arctic Ocean. Over the latter two, these small increases are likely driven by increasing surface temperatures and moisture over the Northern Hemisphere high-latitude regions, promoting increasingly frequent shallow convective activity ${ }^{47}$. Seasonal trends follow the annual accumulation patterns, with the exception of southeastern Asia that experience increases during DJF, but decreases in SON (Supplementary Fig. 2). Trends in CP should be interpreted with caution (especially over the tropics) as reanalysis datasets are prone to systematic errors in this metric ${ }^{40}$. Our results only partially overlap with prior studies that suggested decreases in parts of tropical and subtropical areas over Northern Hemisphere ${ }^{42,48}$, with others indicating increases in the most extreme events or mixed trends ${ }^{49,50}$. 


\section{Vertical wind shear}

Thunderstorm severity is governed by storm organization, a process primarily driven by environmental vertical wind shear ${ }^{13-15}$. A number of studies have confirmed that wind shear between the surface and $6 \mathrm{~km}$ above ground level (BS06) combined with CAPE has value in discriminating between severe and non-severe thunderstorms ${ }^{8-10}$. Sufficient BS06 of at least $15 \mathrm{~m} \mathrm{~s}^{-1}$ promotes long-lived convective modes such as supercells and quasi-linear convective systems that produce the vast majority of tornadoes, damaging winds, and large hail $^{51,52}$.

The climatological distribution of the $50^{\text {th }}$ percentile (P50) of BS06 is well correlated with the baroclinically driven thermal wind, and, thus, the position of the jet streams. The highest values in BS06 are observed across mid-latitudes where horizontal temperature gradients are the highest (Figs. 1c and 3). Conversely, the lowest BS06 occurs along the Equator where the horizontal temperature gradient is very small, and upper level air circulation is comparatively weak. Seasonally, BS06 peaks in the respective hemispheric winters in DJF and JJA (Supplementary Fig. 3). These patterns are generally seasonally reversed relative to CAPE, meaning that weak shear is typically accompanied by high CAPE and vice-versa. However, there are some regional exceptions like the Great Plains of the United States where high CAPE is also accompanied by strong BS06 and creates favorable conditions for severe thunderstorms producing strong tornadoes and very large hail.

Long-term trends in the P50 of BS06 are small both seasonally and annually in comparison to those for instability (Fig. 1C, Supplementary Fig. 3), with modest increases along the ITCZ of $+0.2 \mathrm{~m} \mathrm{~s}^{-1}(\sim 2-5 \%)$ per decade (Figs. 1c and 3), and coincide with areas of decreasing CAPE (Fig. 1a). Wind shear has increased over the Southern Ocean, and the mid-latitudes (southern South America, far southern Africa, the northern United States), where it has shifted slightly poleward. Modest significant decreases have taken place in regions where jet streams are commonplace, including a corridor from eastern Brazil to Australia, southeastern Europe, northern Canada, and the Arctic (Fig. 1c). However, considering seasons with peak convective activity across midlatitudes, changes in BS06 over Southern Hemisphere in DJF are small, while over the Northern Hemisphere in JJA only decreases across Europe and China are significant (Supplementary Fig. 3).

\section{Modeled severe thunderstorm environments}

Combining previously analyzed parameters (CAPE, BS06, CP) into environmental proxies for the occurrence of (severe) thunderstorms over the land surface (similar to the approach of Brooks et al..$^{8}$ and Taszarek et al. ${ }^{35}$ ), we consider changes to the number of hours favorable for convective development each year. More than $1000 \mathrm{~h}$ per year are favorable for the development of thunderstorms along the ITCZ, most frequently over the Amazon Basin, Congo Basin, and far southeastern Asia where peak values exceed even $2000 \mathrm{~h}$ (Figs. 2a and 3). Enhanced frequencies of favorable thunderstorm environments ( $>400 \mathrm{~h}$ per year) occur over the southeastern United States, La Plata Basin, southern China, India, and northern Australia. Over the remainder of the globe, there are typically fewer than $150 \mathrm{~h}$ with favorable thunderstorm environments. Spatial variability has a strong link to the annual cycle with a peak frequency in JJA over the Northern Hemisphere and DJF over the Southern Hemisphere (Supplementary Fig. 4).

Long-term trends in thunderstorm environments predominantly feature robust decreases with the most pronounced reductions over Congo Basin of $-97 \mathrm{~h}$ (10\%) per decade, and Amazon Basin with $-54 \mathrm{~h}$ (3\%) per decade (Figs. 2a and 3). Significant modest decreases of approximately $5 \%$ per decade are also observed across the United States, southeastern Asia, La Plata Basin, and Australia. Increases are minor and confined only to just a few hours per decade in summer over Europe, India, and western China (Supplementary Fig. 4).

Severe thunderstorm environments are more closely tied to the location of jet streams where strong vertical wind shear is available (Fig. 2b). This shifts the peak frequency of severe thunderstorms away from the tropics towards mid-latitudes, predominantly downstream or eastward of significant topography. Regions such as the eastern half of the United States, La Plata Basin, southern Africa, southeastern China, Bangladesh, and southern Europe feature the most conducive environments for severe thunderstorms (Fig. 2b, Fig. 3). The overlap of CAPE and BS06 is especially favorable over La Plata Basin where severe thunderstorm environments occur almost year round with a peak in SON (Supplementary Fig. 5).

Long-term trends of severe environments feature significant changes primarily across mid-latitudes (Fig. 2b). The largest decreases of approximately $-15 \mathrm{~h}(\sim 5-10 \%)$ per decade are observed over La Plata Basin, southeastern China, and the southern Great Plains of the United States (Fig. 3). Minor significant increases of a few hours $(\sim 5 \%)$ per decade are also found over portions of Europe, central Russia, and the northern Great Plains of the United States, seasonally tied to MAM and JJA (Supplementary Fig. 5).

\section{Changes by latitude}

Given the strong relationship between climatological distributions of CAPE, CP, BS06, and latitude (Fig. 1), we also consider this aspect in Fig. 4. Although from the climatological standpoint the largest CAPE is observed between $20^{\circ} \mathrm{S}$ and $20^{\circ} \mathrm{N}$, the most significant decreases over land take place around $20^{\circ} \mathrm{S}$ and $10^{\circ} \mathrm{N}$ with almost no change near the Equator (Fig. 4a). Small increases to CAPE between $40^{\circ} \mathrm{N}$ and $60^{\circ} \mathrm{N}$ are mostly insignificant.

Similar to CAPE, CP has the highest accumulations between $20^{\circ}$ $S$ and $20^{\circ} \mathrm{N}$ coinciding with the seasonal shifts of the ITCZ. However, in contrast to CAPE, well-defined significant decreases in $\mathrm{CP}$ are observed from $50^{\circ} \mathrm{S}$ to $10^{\circ} \mathrm{N}$, with peak decreases near the Equator (Fig. 4b). Increasing convective activity is observed between $60^{\circ} \mathrm{N}$ and $80^{\circ} \mathrm{N}$, most likely as a result of rapid warming and the corresponding increase to moisture at these latitudes ${ }^{47}$.

Vertical wind shear reverses the pattern of CAPE with P50 BS06 below $10 \mathrm{~m} \mathrm{~s}^{-1}$ along latitudes between $20^{\circ} \mathrm{S}$ and $20^{\circ} \mathrm{N}$ (Fig. 4C). Peak values exceeding $15 \mathrm{~m} \mathrm{~s}^{-1}$ are observed in mid-latitudes around $45^{\circ} \mathrm{S}$ and $40^{\circ} \mathrm{N}$. Most trends for BSO6 are not robust, but well-defined significant increases are observed within the ITCZ between $10^{\circ} \mathrm{S}$ and $10^{\circ} \mathrm{N}$. In contrast, significant decreases are identified around $20^{\circ} \mathrm{S}$, reflecting decreases to the subtropical jet stream over southern Africa and Australia. Warming across the high latitudes appears to be driving smaller horizontal temperature gradients $s^{53}$, thereby inducing changes in the Northern Hemisphere polar jet stream between $60^{\circ} \mathrm{N}$ and $70^{\circ} \mathrm{N}^{54,55}$.

Trends in favorable thunderstorm environments provide a clear picture of robust decreases between $50^{\circ} \mathrm{S}$ and $40^{\circ} \mathrm{N}$, with peak reductions observed within the ITCZ (Fig. 4d). However, when the additional ingredient of $\mathrm{BSO6}$ is considered for the severe thunderstorm proxy, there is a noticeable increase around the Equator. In contrast, over the mid-latitudes where severe thunderstorms are more frequent, there are significant decreases between $20^{\circ}$ and $40^{\circ}$ over both hemispheres (Fig. 4e). These changes are larger in the Southern Hemisphere than in the Northern Hemisphere, reflecting the consistent decreases over South America, southern Africa, and eastern Australia. This suggests that although the overall number of favorable thunderstorm situations has been steadily decreasing across ITCZ, the fraction of environments supportive of severe weather relatively increased. 


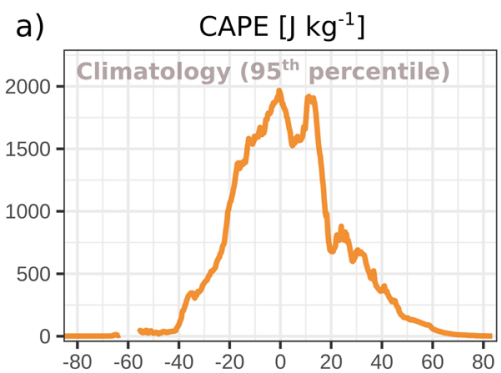

b) Convective precipitation $[\mathrm{mm}]$

C) $\quad 0-6 \mathrm{~km}$ wind shear $\left[\mathrm{m} \mathrm{s}^{-1}\right]$
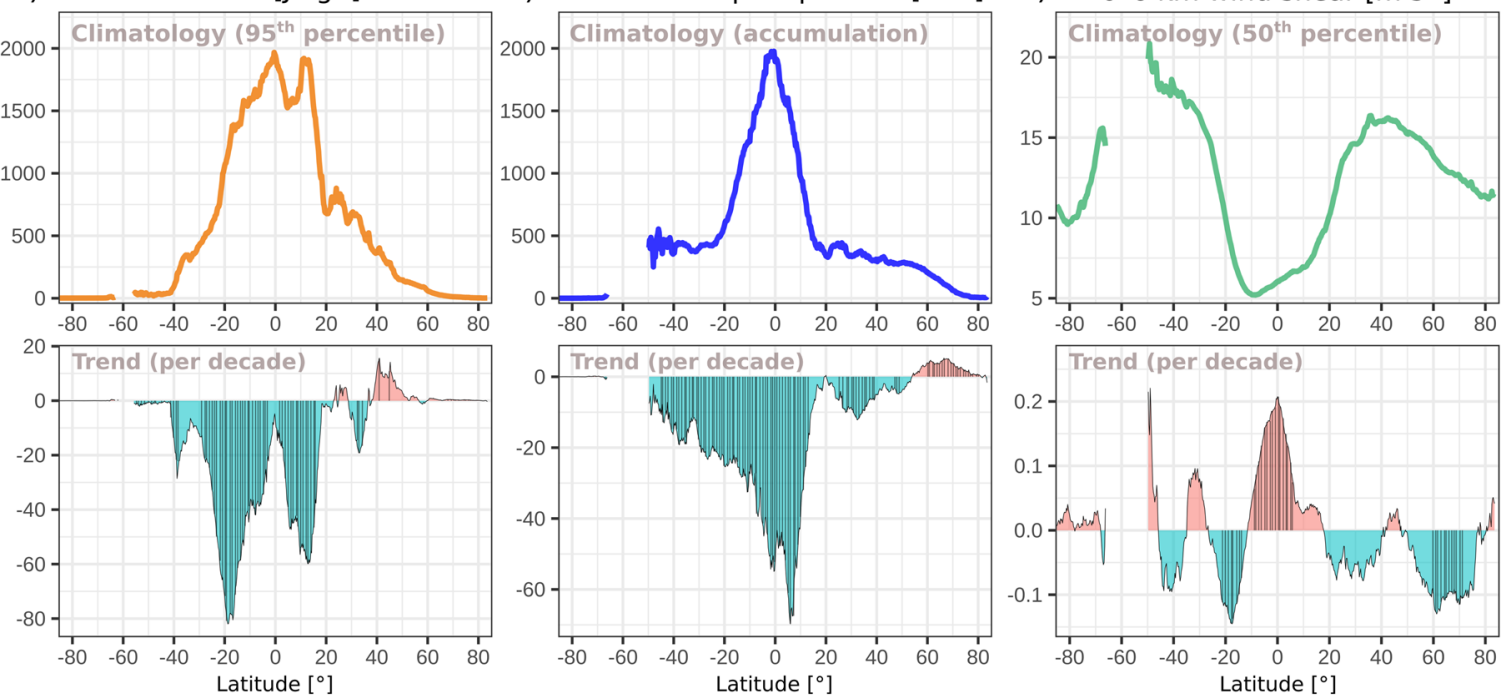

d) Thunderstorm environments [hours]**

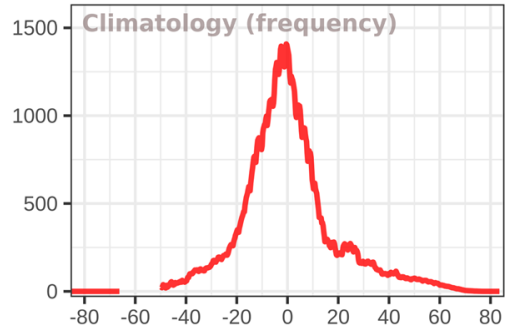

e) Severe environments [hours]***
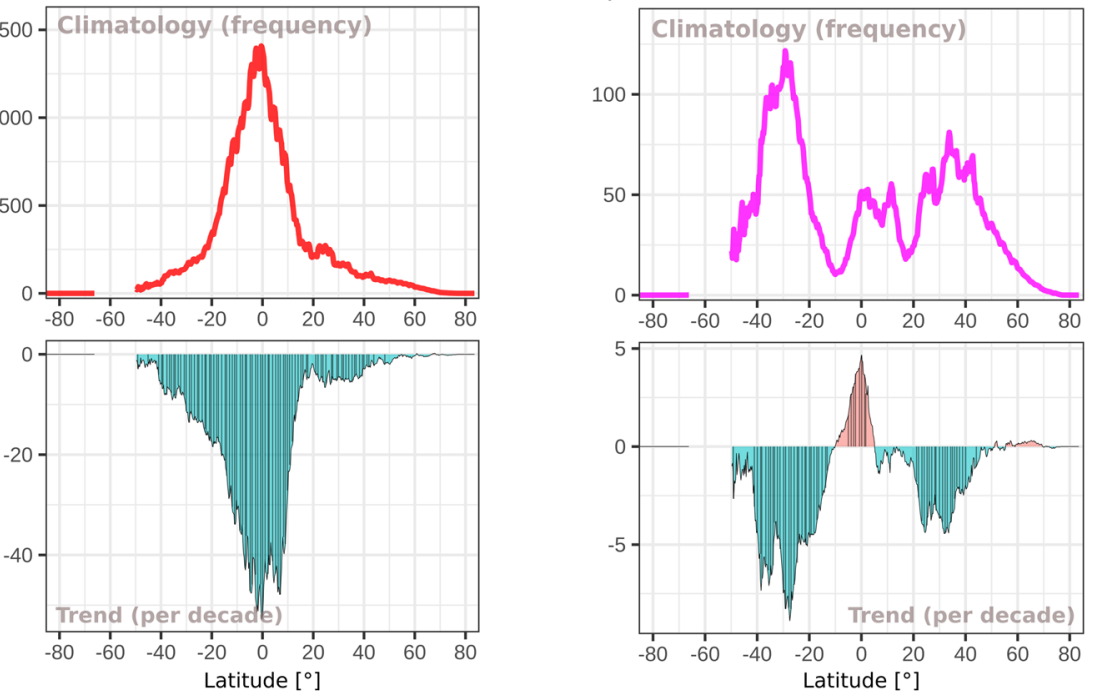

* - Vertical black lines indicate trend with p-value $<0.05$

** - Thunderstorm environments is considered when CAPE $>150 \mathrm{~J} \mathrm{~kg}^{-1}$ and CP $>0.25 \mathrm{~mm} \mathrm{~h}^{-1}$

*** - Severe thunderstorm environments is considered when CAPE $>150 \mathrm{~J} \mathrm{~kg}^{-1}, 0-6 \mathrm{~km}$ wind shear $>12.5 \mathrm{~m} \mathrm{~s}^{-1}$ and $\mathrm{CP}>0.25 \mathrm{~mm} \mathrm{~h}$

Fig. 4 ERA5 zonal mean climatology and trends for CAPE, convective precipitation, vertical wind shear, thunderstorm and severe thunderstorm environments (land surface grids only). A 41-year (1979-2019) zonal mean climatology and trends for (a) $95^{\text {th }}$ percentile of convective available potential energy (CAPE), (b) accumulated convective precipitation, (c) $50^{\text {th }}$ percentile of 0-6 km vertical wind shear, (d) frequency of thunderstorm environments, and (e) frequency of severe thunderstorm environments. Only grids over the land surface are taken into account (at least 30 in any latitudinal band). Trend is computed using Sen's slope and value denote change per decade. Vertical solid lines indicate p-value below 0.05 .

\section{Comparison with rawinsonde data}

Validation of ERA5 with trends obtained from observed global sounding measurements provides greater context to the certainty of ERA5 results, and identifies which aspects should be interpreted with caution. However, it should be noted that rawinsonde observations are also not free of errors. This includes temporal inhomogeneities, limited spatial availability (most of the stations are from mid-latitudes) and limited sub-daily sampling (0000 and 1200 UTC), contrasting the hourly resolution of ERA $5^{39,56}$.

Trends in P50 BS06 derived from quality-controlled sounding measurements for stations with sufficient temporal record are generally in a good agreement with ERA5 (Fig. 5b). Robust decreases are observed over parts of Europe, Southeastern Asia, and Australia while modest and mostly insignificant changes occur over North America. Problematically, the availability of rawinsonde data from South America and Africa is too limited to derive reliable conclusions for trends across broader areas.

Larger discrepancies are observed for trends in P95 CAPE. In sounding data, there are robust increases over Southeastern Asia and Australia, which is contrasted by the opposite pattern in ERA5 (Fig. 5a). Over Europe and North America trends in P95 of CAPE are mixed in both datasets, especially when time steps of 0000 and 1200 UTC for rawinsondes are compared. These results are broadly consistent with prior studies indicating that vertical wind shear is represented well in reanalyses, while thermodynamic indices like CAPE (especially extremes such as P95) are less reliable ${ }^{37-39}$. Thus, it is difficult to validate whether trends in instability in ERA5 are realistic, especially over tropics and subtropics. 
a)

Trend (per decade)*

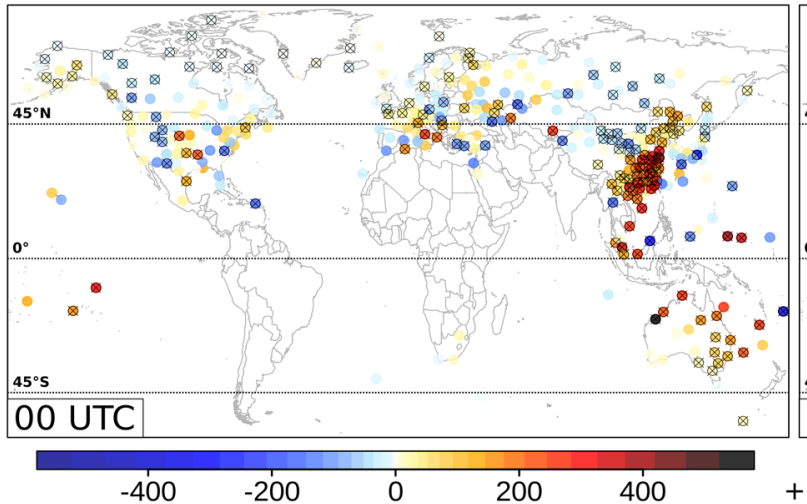

Trend (per decade)*

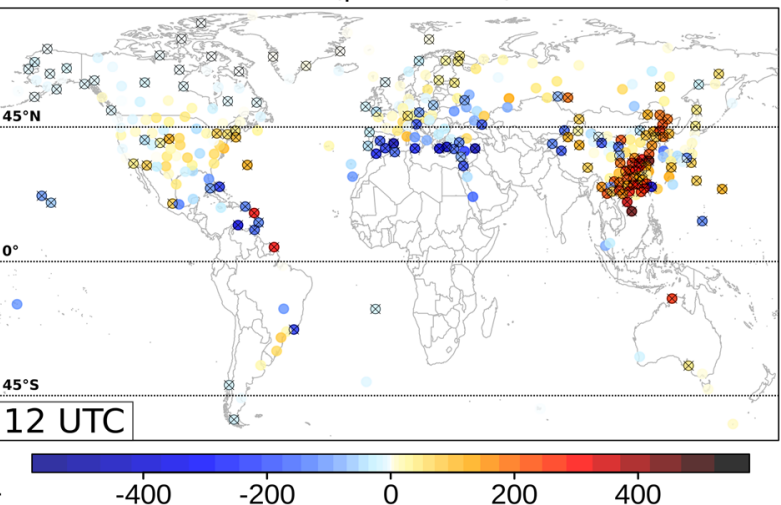

b)

$50^{\text {th }}$ percentile of $0-6 \mathrm{~km}$ shear $\left[\mathrm{m} \mathrm{s}^{-1}\right]$ - observations
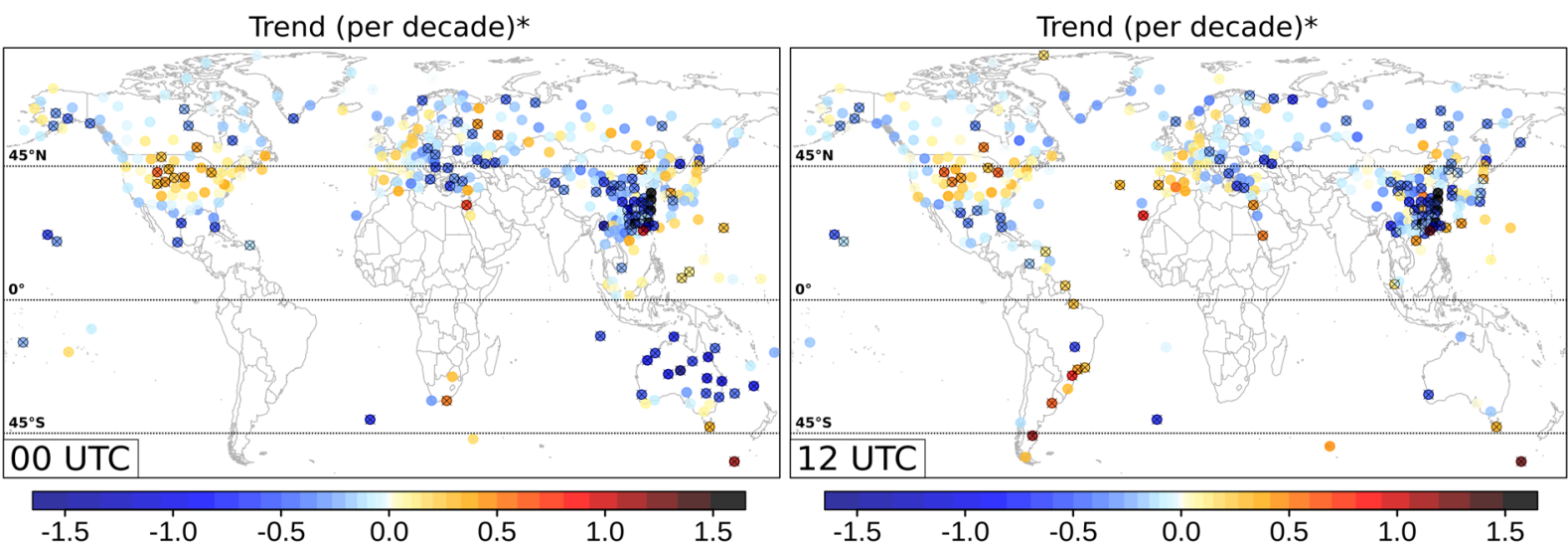

* - ' $x$ ' marks denote statistically significant trend ( $p$-value $<0.05$ )

c)

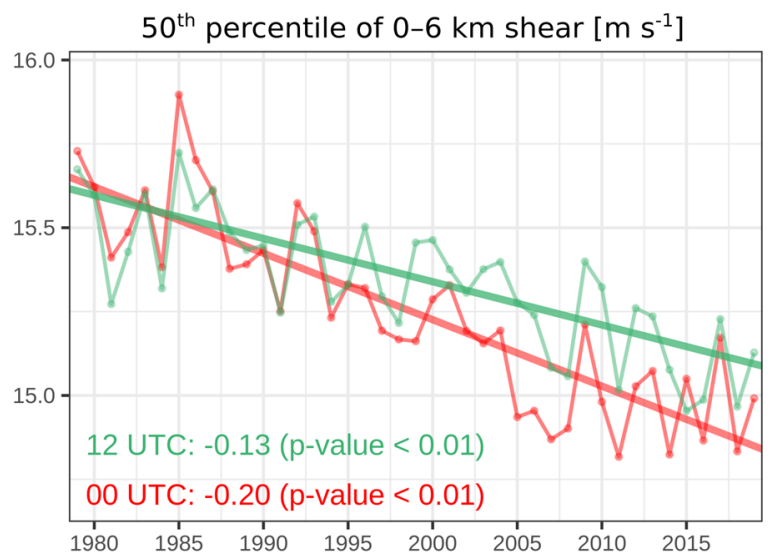

Trends** on the global scale (all observations combined) $95^{\text {th }}$ percentile of CAPE [J kg-1]

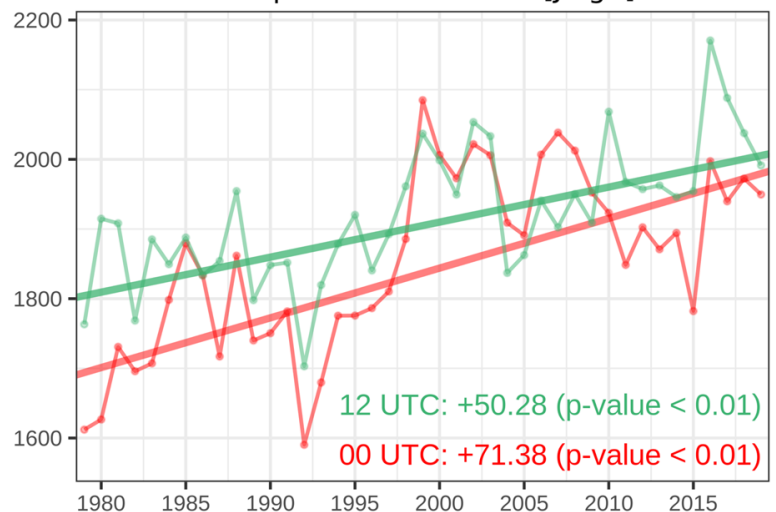

** - trend values denote change per decade (including only rawinsonde stations with at least 10000 measurements for 00 or 12 UTC)

Fig. 5 Rawinsonde trends for CAPE and vertical wind shear. A 41-year (1979-2019) 0000 and 1200 UTC trends for (a) $95^{\text {th }}$ percentile of convective available potential energy (CAPE), and (b) $50^{\text {th }}$ percentile of $0-6 \mathrm{~km}$ vertical wind shear. Trends for all rawinsonde observations combined together are presented on (c). Trend is computed using Sen's slope and value denote change per decade. Only stations that passed a rigorous quality-control procedure with at least 10000 observations available for 0000 or 1200 UTC (at least 100 per year over 30 years) are included in this analysis.

Combining all quality-controlled rawinsonde measurements suggest that over the last 4 decades P95 CAPE has been consistently increasing, while an opposite pattern was observed for P50 BS06 - both are statistically significant for both 0000 and 1200 UTC (Fig. 5c). This result broadly confirms previous expectations based on climate simulations ${ }^{57-59}$. However, it is worth noting that the majority of stations evaluated in our study with good temporal coverage are from mid-latitudes, and thus evaluation of changes across the tropics is limited. 


\section{DISCUSSION}

In this study, we evaluated global thunderstorm environments and their corresponding trends over the 41 year period (1979-2019) by using ERA5 reanalysis and rawinsonde observations. Although ERA5 is only a modeled approximation of real atmospheric conditions, it provides a continuous dataset in time and space with resolution allowing construction of climatologies in a way that was not possible with prior global reanalyses.

Based on results from ERA5, CP over the world's second-largest rainforest in the Congo Basin, has decreased by $25 \%$ in the annual mean from $1700 \mathrm{~mm}$ in the $1980 \mathrm{~s}$ to $1300 \mathrm{~mm}$ in the last decade. Changes over other tropical regions such as the Amazon Basin or southeastern Asia also feature decreases but with a smaller overall magnitude of change (10\%). These changes are also accompanied by decreases in available energy represented by CAPE, and thus imply a lower frequency of environments favorable to thunderstorms with potential implications for water availability ${ }^{60}$, agricultural productivity, societal aspects, and desertification (e.g. Sahel region ${ }^{41}$ ).

However, these results are in contrast to the current expectations of changes in response to a globally warming climate in CMIP5 projections, where an increase in heavy precipitation (but also increased length of dry periods) across tropics is anticipated $^{28-31}$. Previous research has argued that robust weakening of the tropical circulation is seen across models, and that changes in the spatial pattern of precipitation are dominated by the shifts across convergence zones. However, as concluded by Kent et al. ${ }^{29}$ and Huang et al. ${ }^{34}$, projected changes in CP over tropical and subtropical regions in a future climate are highly uncertain, with models disagreeing even on the sign of trends. The same applies to ERA5 where systematic errors in $\mathrm{CP}$ are also present. Large uncertainties in simulating convection and cloud ice fundamental to lightning formation in global climate models were also noted by Finney et al. ${ }^{61}$. Similar to our study, they found reductions in lightning days in Congo, but an increase in extreme lightning days.

Mid-latitude changes to CAPE vary considerably in space, with modest decreases over the Southern Hemisphere and robust positive trends close to inland seas, over Europe, and the northern Great Plains of the United States. Despite these increases, there are overall reductions in $\mathrm{CP}$, and regional modulations in $\mathrm{BS} 06$. However, even with positive trends in BS06 over the La Plata Basin and Southern Africa, the frequency of severe thunderstorm environments decreased due to less frequent convective development according to ERA5. Conversely, at higher latitudes, positive trends in CAPE and CP (e.g. southern Europe), contribute to increases in severe environments despite steadily decreasing BS06. This suggests that a prime consideration for assessing longterm changes to thunderstorm frequency needs to focus on convective initiation and its efficiency ${ }^{35,45,62}$ rather than just the other ingredients, which is challenging to assess with observational data. Trends derived from rawinsonde observations for 0000 and 1200 UTC indicate significant increases in CAPE and reductions in $\mathrm{BS} 06$ across mid-latitudes, consistent with expectations of a changing climate ${ }^{57-59}$. However, by the same token, this also highlights that trends in the ERA5 reanalysis should be considered carefully, as they are not always consistent with observed records.

A likely driver of some of these changes is a globally increasing near-surface temperature and moisture that has accelerated since the 1980s, especially considering high latitudes of the Northern Hemisphere ${ }^{41}$. A significant increase in $\mathrm{CP}$ accumulations between $60^{\circ} \mathrm{N}$ and $80^{\circ} \mathrm{N}$ may be indicative of more frequent thunderstorms in very high latitudes as documented observationally by Houze et al. ${ }^{63}$ and Brown et al. ${ }^{64}$. Changes in the horizontal temperature gradients are also another important factor that influences strength and position of the mid-latitude jet streams ${ }^{53-55}$, that are a main driver of severe thunderstorms.

The disagreement between our results and CMIP5 projections of changes to convective environments by the end of the century may be a result of temporal inhomogeneities in the ERA5, an aspect of climate variability on the multi-decadal scale, or strong uncertainties in simulated future CP accumulations in $\mathrm{GCMs}^{29}$. Recent changes in atmospheric aerosols may be also a reason why historical trends in ERA5 differ from the projected climate change response. As reanalysis records continue to lengthen, they will allow improved assessment of historical changes in convective environments, and provide greater context for projected scenarios in climate projections. Nevertheless, the ERA5 results presented here suggest that despite substantial increases in temperature since the 1980s, fewer favorable thunderstorm environments are occurring over some regions, in contrast to the increases expected in a warmer future climate. Other factors such as future expected decreases in vertical wind shear, relative humidity, and temperature lapse rates can also have a negative effect on the likelihood of convective storms and their severity, but large uncertainties in the models limit our confidence.

\section{METHODS}

\section{Reanalysis dataset}

In this work, we use the $5^{\text {th }}$ generation of ECMWF (The European Centre for Medium Range Weather Forecasts) global reanalysis $\left(E R A 5^{65,66}\right.$ ) over a period of 41 years (1979-2019). In comparison to its predecessor (ERAInterim), ERA5 has improved spatial $\left(0.75^{\circ}\right.$ to $\left.0.25^{\circ}\right)$, vertical (60 to 137 levels), and temporal (6-h to 1-h) spacing, which allows a better representation of the small scale features associated with convective environments that are sensitive to the resolution of numerical data.

\section{Rawinsonde dataset}

All available sounding observations over a period of 41 years (1979-2019) were firstly derived from 1363 stations on a global scale ( 17 mln measurements) from the University of Wyoming database. After strict quality-control procedures (explained in details in Taszarek et al. $^{39}$ ), we chose only those stations that had at least 10000 observations (no less than 100 per year for at least 30 years) for 0000 or 1200 UTC time steps (i.e. where a credible trend computation was possible). A final database consisted of 4,552,307 profiles from 362 stations for 0000 UTC, and $4,110,860$ profiles from 329 stations for 1200 UTC (Supplementary Fig. 7). An increasing quality of rawinsonde measurements was observed with time as a higher fraction of profiles passed quality-control procedures over the recent years compared to 1980 s and 1990s.

\section{Definition of environmental proxies}

Following an ingredient-based approach commonly applied in researching and forecasting severe thunderstorms ${ }^{7}$, here we evaluate 3 variables: (1) convective available potential energy (CAPE), which determines whether an atmosphere has a potential to produce robust convective updrafts, (2) $0-6 \mathrm{~km}$ vertical wind shear (BS06) that governs storm organization, and (3) ERA5 simulated convective precipitation (CP) used as a proxy for convective initiation ${ }^{16,17,35}$. The underlying ERA5 convective parameterization that produces $\mathrm{CP}^{67}$ applies a mass flux closure scheme with entrainment that triggers convection based on either surface fluxes or synoptic-scale motion, thereby providing greater confidence of initiation in a manner similar to the observed atmosphere.

In addition to individual variables, we also combine them into specific proxies to define conditions favorable to (severe) thunderstorms. Based on prior research ${ }^{8,35,58,68}$, we consider a thunderstorm environment favorable if CAPE $>150 \mathrm{~J} \mathrm{~kg}^{-1}$ and $\mathrm{CP}>0.25 \mathrm{~mm} \mathrm{~h}^{-1}$, and a severe thunderstorm environment favorable if in addition BS06 $>12.5 \mathrm{~m} \mathrm{~s}^{-1}$. Combining CAPE with vertical wind shear has been previously shown to distinguish well between non-severe, severe and significant severe thunderstorms across the United States ${ }^{10,57}$, Australia ${ }^{9}$, Europe ${ }^{10}$, South Africa ${ }^{69}$, and South America $^{70}$. As these proxies have been originally developed for severe thunderstorms occurring over the land surface, in this study oceanic environments are not considered. Another important aspect is that the majority of these proxies were designed based on mid-latitudes, thus their 
application in tropical and sub-tropical areas should be interpreted with caution.

All variables were considered for the global domain at hourly resolution. CAPE and CP were retrieved from the Copernicus Climate Data Store ${ }^{65}$ while BS06 was calculated by interpolating $\mathrm{U}$ and $\mathrm{V}$ winds to the height profile from the native model level data, and taking the magnitude of the vector difference between $10 \mathrm{~m}$ and $6000 \mathrm{~m}$ above ground level.

\section{Computation of climatology and trends}

To assess climatology and trends, we use 4 different metrics describing important elements of the environmental distribution: accumulation (for $\mathrm{CP}$ ), $50^{\text {th }}$ percentile (for BS06), $95^{\text {th }}$ percentile (for CAPE) and frequency of favorable (severe) thunderstorm environments. These metrics are consistent with similar prior studies that evaluated convective trends on the regional scale ${ }^{35,36,68}$. Climatology is defined by taking into account the mean from all annual or seasonal values of those metrics, while trends are assessed by applying the non-parametric Sen's slope analysis ${ }^{71}$. We chose this metric due to its frequent application for evaluating robust trends in the atmospheric sciences where the underlying parameters exhibit interannual variability. Significance of the trend is assessed using a non-parametric Mann-Kendall two-tailed $p$-value at the 0.05 threshold that is denoted by stippled ' $x$ ' on each figure. Slope units are calculated for the annual change, but normalized to change per decade for simplicity of interpretation.

\section{LIMITATIONS}

Environmental proxies are an imperfect conditional approximation of convective activity, and should be interpreted with caution. As demonstrated by Tippett et al. ${ }^{17}$ performance of such proxies varies by region and time of the year considered. This poses challenges, particularly when comparing different parts of the world with different underlying climatology. Proxies used in this study were primarily developed for the mid-latitudes, and their performance over tropical and subtropical areas is uncertain. Thus, analyzing changes using these proxies will be burdened with some degree of inaccuracy, no matter the parameter chosen. Application of convective proxies obviously does not provide an explicit number of storm events, but it helps to define the approximate frequency to those that may most likely result in (severe) thunderstorms.

Additional limitations may be related to the model formulation of ERA5. For example, convective parameterizations may lead to errors in the vertical profile of temperature and moisture and subsequently influence metrics such as CAPE and modeled precipitation ${ }^{25,37-39}$. Although the defining concept of the reanalysis is to provide a consistent record of meteorological conditions over time, varying quality of assimilated data may be a source of specific biases that are smaller over the recent years ${ }^{66,72}$. Although it is beyond the scope of this paper to diagnose the source of such errors, it provides a caveat on the results and should be taken into consideration when interpreting results, especially over areas where differing trends are obtained for observations. Nevertheless, ERA5 at least regionally compared to other global reanalyses is considered to be currently one of the best available tools for studying convective climatologies ${ }^{35,36,39}$.

\section{DATA AVAILABILITY}

ERA5 hourly data (convective available potential energy, accumulated convective precipitation, $\mathrm{U}$ and $\mathrm{V}$ on native model levels) was downloaded from the European Centre for Medium-Range Weather Forecasts (ECMWF), Copernicus Climate Change Service (C3S) at Climate Data Store (CDS; https://cds.climate.copernicus.eu/). Radiosonde data was downloaded from the University of Wyoming upper air database available at http://weather.uwyo.edu/upperair/.

Received: 16 April 2021; Accepted: 21 May 2021; Published online: 11 June 2021

\section{REFERENCES}

1. Munich Re. 2020. Thunderstorms, hail and tornadoes. Localised but extremely destructive. Available online: https://www.munichre.com/en/risks/natural-disasterslosses-are-trending-upwards/thunderstorms-hail-and-tornados.html (accessed on 31 Aug 2020).

2. Terti, G. et al. Toward probabilistic prediction of flash flood human impacts. Risk Anal. 39, 140-161 (2019).

3. Holle, R. L. A summary of recent national-scale lightning fatality studies. Wea. Clim. Soc. 8, 35-42 (2016).

4. Prein, A. F. \& Holland, G. J. Global estimates of damaging hail hazard. Weather Clim. Extremes 22, 10-23 (2018).

5. Schoen, J. M. \& Ashley, W. S. A climatology of fatal convective wind events by storm type. Wea. Forecast. 26, 109-121 (2011).

6. Antonescu, B., Schultz, D. M., Holzer, A. \& Groenemeijer, P. Tornadoes in Europe: an underestimated threat. Bull. Am. Meteorol. Soc. 98, 713-728 (2017).

7. Johns, R. H. \& Doswell, C. A. III Severe local storms forecasting. Wea. Forecast. 7, 588-612 (1992).

8. Brooks, H. E., Lee, J. W. \& Craven, J. P. The spatial distribution of severe thunderstorm and tornado environments from global reanalysis data. Atmos. Res. 67, 73-94 (2003).

9. Allen, J. T., Karoly, D. J. \& Mills, G. A. A severe thunderstorm climatology for Australia and associated thunderstorm environments. Aust. Meteorological Oceanographic J. 61, 143-158 (2011).

10. Taszarek, M., Allen, J. T., Púčik, T., Hoogewind, K. A. \& Brooks, H. E. Severe convective storms across Europe and the United States. Part II: ERA5 environments associated with lightning, large hail, severe wind, and tornadoes. J. Clim. 33, 10263-10286 (2020).

11. Emanuel, K. A. Atmospheric convection. Oxford University Press, 558 pp (1994).

12. Riemann-Campe, K., Fraedrich, K. \& Lunkeit, F. Global climatology of Convective Available Potential Energy (CAPE) and Convective Inhibition (CIN) in ERA-40 reanalysis. Atmos. Res. 93, 534-545 (2009).

13. Weisman, M. L. \& Klemp, J. B. The dependence of numerically simulated convective storms on vertical wind shear and buoyancy. Mon. Weather Rev. 110, 504-520 (1982).

14. Warren, R. A., Richter, H., Ramsay, H. A., Siems, S. T. \& Manton, M. J. Impact of variations in upper-level shear on simulated supercells. Mon. Weather Rev. 145, 2659-2681 (2017).

15. Peters, J. M., Nowotarski, C. J. \& Morrison, H. The role of vertical wind shear in modulating maximum supercell updraft velocities. J. Atmos. Sci. 76, 3169-3189 (2019).

16. Romps, D. M. et al. CAPE times $P$ explains lightning over land but not the landocean contrast. Geophys. Res. Lett. 45, 12-623 (2018).

17. Tippett, M. K., Lepore, C., Koshak, W. J., Chronis, T. \& Vant-Hull, B. Performance of a simple reanalysis proxy for US cloud-to-ground lightning. Int. J. Climatol. 39, 3932-3946 (2019).

18. Price, C. \& Asfur, M. Inferred long term trends in lightning activity over Africa. Earth, Planet Sp. 58, 1197-1201 (2006).

19. Kunz, M., Sander, J. \& Kottmeier, C. Recent trends of thunderstorm and hailstorm frequency and their relation to atmospheric characteristics in southwest Germany. Int. J. Climatol. 29, 2283-2297 (2009).

20. Pinto, O. Jr, Pinto, I. R. C. A. \& Ferro, M. A. S. A study of the long-term variability of thunderstorm days in southeast Brazil. J. Geophys. Res.: Atmos. 118, 5231-5246 (2013).

21. Lavigne, T., Liu, C. \& Liu, N. How Does the Trend in Thunder Days Relate to the Variation of Lightning Flash Density? J. Geophys. Res.: Atmos. 124, 4955-4974 (2019).

22. Harel, M. \& Price, C. Thunderstorm Trends over Africa. J. Clim. 33, 2741-2755 (2020).

23. Diffenbaugh, N. S., Scherer, M. \& Trapp, R. J. Robust increases in severe thunderstorm environments in response to greenhouse forcing. Proc. Natl Acad. Sci. USA 110, 16361-16366 (2013).

24. Seeley, J. T. \& Romps, D. M. Why does tropical convective available potential energy (CAPE) increase with warming? Geophys. Res. Lett. 42, 10,429-10,437 (2015).

25. Allen, J. T. Climate change and severe thunderstorms. Oxford Research Encyclopedia of Climate Science, $67 \mathrm{pp}$ (2018).

26. Chen, J., Dai, A., Zhang, Y. \& Rasmussen, K. L. Changes in convective available potential energy and convective inhibition under global warming. J. Clim. 33, 2025-2050 (2020).

27. Glazer, R. H. et al. Projected changes to severe thunderstorm environments as a result of twenty-first century warming from RegCM CORDEX-CORE simulations. Clim. Dyn. https://doi.org/10.1007/s00382-020-05439-4. (2020).

28. Chadwick, R., Boutle, I. \& Martin, G. Spatial patterns of precipitation change in CMIP5: why the rich do not get richer in the tropics. J. Clim. 26, 3803-3822 (2013). 
29. Kent, C., Chadwick, R. \& Rowell, D. P. Understanding uncertainties in future projections of seasonal tropical precipitation. J. Clim. 28, 4390-4413 (2015).

30. Liu, H. W., Yu, J. Y. \& Chen, C. A. Changes of tropical precipitation and convective structure under global warming projected by CMIP5 model simulations. Terr. Atmos. Ocean. Sci. 29, 429-440 (2018).

31. Creese, A., Washington, R. \& Jones, R. Climate change in the Congo Basin: processes related to wetting in the December-February dry season. Clim. Dyn. 53, 3583-3602 (2019).

32. Finney, D. L. et al. A projected decrease in lightning under climate change. Nat. Clim. Change 8, 210-213 (2018).

33. Romps, D. M. Evaluating the future of lightning in cloud-resolving models. Geophys. Res. Lett. 46, 14863-14871 (2019).

34. Huang, D. et al. Uncertainty of global summer precipitation in the CMIP5 models: a comparison between high-resolution and low-resolution models. Theor. Appl. Climatol. 132, 55-69 (2018).

35. Taszarek, M., Allen, J. T., Brooks, H. E., Pilguj, N. \& Czernecki, B. Differing trends in United States and European severe thunderstorm environments in a warming climate. Bull. Am. Meteorol. Soc. 102, 296-322 (2021).

36. Li, F., Chavas, D. R., Reed, K. A. \& Dawson, D. T. Climatology of severe local storm environments and synoptic-scale features over North America in ERA5 reanalysis and CAM6 simulation. J. Clim. 33, 8339-8365 (2020).

37. Gensini, V. A., Mote, T. L. \& Brooks, H. E. Severe-thunderstorm reanalysis environments and collocated radiosonde observations. J. Appl. Meteorol. Climatol. 53, 742-751 (2014)

38. King, A. T. \& Kennedy, A. D. North American supercell environments in atmospheric reanalyses and RUC-2. J. Appl. Meteor. Climatol. 58, 71-92 (2019)

39. Taszarek, M. et al. Comparison of convective parameters derived from ERA5 and MERRA2 with sounding data over Europe and North America. J. Clim 34, 3211-3237 (2021)

40. Cui, W., Dong, X., Xi, B. \& Kennedy, A. Evaluation of reanalyzed precipitation variability and trends using the gridded gauge-based analysis over the CONUS. $J$. Hydrometeor. 18, 2227-2248 (2017).

41. D'Odorico, P., Bhattachan, A., Davis, K. F., Ravi, S. \& Runyan, C. W. Global desertification: drivers and feedbacks. Adv. Water Resour. 51, 326-344 (2013).

42. Zhang, $X$. et al. Detection of human influence on twentieth-century precipitation trends. Nature 448, 461-465 (2007).

43. Groenemeijer, P. et al. Severe convective storms in Europe: ten years of research and education at the European Severe Storms Laboratory. Bull. Am. Meteorol. Soc. 98, 2641-2651 (2017).

44. Trapp, R. J. \& Hoogewind, K. A. The realization of extreme tornadic storm events under future anthropogenic climate change. J. Clim. 29, 5251-5265 (2016)

45. Hoogewind, K. A., Baldwin, M. E. \& Trapp, R. J. The impact of climate change on hazardous convective weather in the United States: insight from high-resolution dynamical downscaling. J. Clim. 30, 10081-10100 (2017).

46. Li, R. C. \& Zhou, W. Changes in western Pacific tropical cyclones associated with the El Niño-Southern Oscillation cycle. J. Clim. 25, 5864-5878 (2012).

47. IPCC: Global Warming of $1.5^{\circ} \mathrm{C}$ An IPCC Special Report on the Impacts of Global Warming of $1.5^{\circ} \mathrm{C}$ Above Pre-Industrial Levels and Related Global Greenhouse Gas Emission Pathways, in the Context of Strengthening the Global Response to the Threat of Climate Change. Sustainable Development, and Efforts to Eradicate Poverty. IPCC (2018).

48. Gu, G. \& Adler, R. F. Spatial patterns of global precipitation change and variability during 1901-2010. J. Clim. 28, 4431-4453 (2015)

49. Maidment, R. I., Allan, R. P. \& Black, E. Recent observed and simulated changes in precipitation over Africa. Geophys. Res. Lett. 42, 8155-8164 (2015).

50. Sheikh, M. M. et al. Trends in extreme daily rainfall and temperature indices over South Asia. Int. J. Climatol. 35, 1625-1637 (2015).

51. Thompson, R. L., Smith, B. T., Grams, J. S., Dean, A. R. \& Broyles, C. Convective modes for significant severe thunderstorms in the contiguous United States. Part II: Supercell and QLCS tornado environments. Wea. Forecast. 27, 1136-1154 (2012).

52. Kumjian, M. R. \& Lombardo, K. A hail growth trajectory model for exploring the environmental controls on hail size: model physics and idealized tests. J. Atmos. Sci. 77, 2765-2791 (2020).

53. Coumou, D., Lehmann, J. \& Beckmann, J. The weakening summer circulation in the northern hemisphere mid-latitudes. Science 348, 324-327 (2015).

54. Pena-Ortiz, C., Gallego, D., Ribera, P., Ordonez, P. \& Alvarez-Castro, M. D. C. Observed trends in the global jet stream characteristics during the second half of the 20th century. J. Geophys. Res.: Atmos. 118, 2702-2713 (2013).

55. Barnes, E. A. \& Screen, J. A. The impact of Arctic warming on the midlatitude jetstream: can it? Has it? Will it? WIREs Clim. Change 6, 277-286 (2015).

56. Zhou, C., Wang, J., Dai, A. \& Thorne, P. W. A new approach to homogenize global subdaily radiosonde temperature data from 1958 to 2018. J. Clim. 34, 1163-1183 (2021).
57. Brooks, H. E. Severe thunderstorms and climate change. Atmos. Res. 123, 129-138 (2013).

58. Trapp, R. J. et al. Changes in severe thunderstorm environment frequency during the 21 st century caused by anthropogenically enhanced global radiative forcing. Proc. Natl Acad. Sci. USA 104, 19719-19723 (2007).

59. Del Genio, A. D., Yao, M.-S. \& Jonas, J. Will moist convection be stronger in a warmer climate? Geophys. Res. Lett. 34, L16703 (2007).

60. Rasmussen, K. L., Chaplin, M. M., Zuluaga, M. D. \& Houze, R. A. Contribution of extreme convective storms to rainfall in South America. J. Hydrometeor. 17, 353-367 (2016).

61. Finney, D. L. et al. African lightning and its relation to rainfall and climate change in a convection-permitting model. Geophys. Res. Lett. 47, e2020GL088163 (2020).

62. Rasmussen, K. L., Prein, A. F., Rasmussen, R. M., Ikeda, K. \& Liu., C. Changes in the convective population and thermodynamic environments in convectionpermitting regional climate simulations over the United States. Clim. Dyn. 55, 383-408 (2020).

63. Houze, R. A. Jr, Wang, J., Fan, J., Brodzik, S. \& Feng, Z. Extreme convective storms over high-latitude continental areas where maximum warming is occurring. Geophys. Res. Lett. 46, 4059-4065 (2019).

64. Brown, D. M., Kochtubajda, B. \& Said, R. K. A severe thunderstorm outbreak north of $70^{\circ} \mathrm{N}$ Over the Canadian Arctic Islands with unusual lightning characteristics. Atmos. Ocean 58, 231-242 (2020).

65. Copernicus Climate Change Service (C3S). ERA5: Fifth generation of ECMWF atmospheric reanalyses of the global climate. Copernicus Climate Change Service Climate Data Store (CDS), https://cds.climate.copernicus.eu/cdsapp\#!/home (access on 15 July 2020).

66. Hersbach, $\mathrm{H}$. et al. The ERA5 global reanalysis. Q. J. R. Meteorol. Soc. 146, 1999-2049 (2020).

67. Bechtold, P. et al. Representing equilibrium and nonequilibrium convection in large-scale models. J. Atmos. Sci. 71, 734-753 (2014).

68. Rädler, A. T., Groenemeijer, P. H., Faust, E., Sausen, R. \& Púčik, T. Frequency of severe thunderstorms across Europe expected to increase in the 21 st century due to rising instability. npj Clim. Atmos. Sci. 2, 1-5 (2019).

69. Blamey, R. C., Ramos, A. M., Trigo, R. M., Tomé, R. \& Reason, C. J. C. The influence of atmospheric rivers over the South Atlantic on winter rainfall in South Africa. J. Hydrometeor. 19, 127-142 (2018).

70. Bruick, Z. S., Rasmussen, K. L. \& Cecil, D. J. Subtropical South American hailstorm characteristics and environments. Mon. Weather Rev. 147, 4289-4304 (2019).

71. Wilcox, R. R. Fundamentals of Modern Statistical Methods: Substantially Improving Power and Accuracy. Springer, 249 pp (2010).

72. Thorne, P. \& Vose, R. Reanalyses suitable for characterizing long-term trends: are they really achievable? Bull. Am. Meteorol. Soc. 91, 353-361 (2010).

\section{ACKNOWLEDGEMENTS}

M.T. acknowledges support from the Polish National Science Centre under Grant No. 2017/27/B/ST10/00297. J.T. Allen acknowledges support from the National Science Foundation under Grant No. AGS-1945286. M.M. acknowledges support from the Italian Ministry of University and Research (MIUR) under grant "Dipartimenti di Eccellenza (2018-2022)", awarded to the Department of Civil, Environmental and Mechanical Engineering of the University of Trento. The reanalysis and sounding computations were performed in the Poznań Supercomputing and Networking Center (project number: 331). Additional funding was provided by the NOAA/Office of Oceanic and Atmospheric Research under NOAA University of Oklahoma Cooperative Agreement NA11OAR4320072, under the U.S. Department of Commerce.

\section{AUTHOR CONTRIBUTIONS}

M.T. designed the study, performed the calculation and visualization of results and led writing of the manuscript. M.M contributed to data collection and processing. J.T. A., M.M., and H.E.B. contributed to the research design, participated in the interpretation of results and writing of the manuscript.

\section{COMPETING INTERESTS}

The authors declare no competing interests.

\section{ADDITIONAL INFORMATION}

Supplementary information The online version contains supplementary material available at https://doi.org/10.1038/s41612-021-00190-x.

Correspondence and requests for materials should be addressed to M.T. 
Reprints and permission information is available at http://www.nature.com/ reprints

Publisher's note Springer Nature remains neutral with regard to jurisdictional claims in published maps and institutional affiliations.

(i) Open Access This article is licensed under a Creative Commons Attribution 4.0 International License, which permits use, sharing, adaptation, distribution and reproduction in any medium or format, as long as you give appropriate credit to the original author(s) and the source, provide a link to the Creative Commons license, and indicate if changes were made. The images or other third party material in this article are included in the article's Creative Commons license, unless indicated otherwise in a credit line to the material. If material is not included in the article's Creative Commons license and your intended use is not permitted by statutory regulation or exceeds the permitted use, you will need to obtain permission directly from the copyright holder. To view a copy of this license, visit http://creativecommons. org/licenses/by/4.0/.

(c) The Author(s) 2021 